\title{
Progress Preservation Techniques Loquat Harvest
}

\author{
Qianqian Ma ${ }^{\mathrm{a}}$, Wanyun Peng ${ }^{\mathrm{b}}$, Zhide Wang ${ }^{\mathrm{c}}$, Zhengwei Xie ${ }^{\mathrm{d}}$, and Yexing Sun ${ }^{\mathrm{e}}$ \\ Dazhou Academy of Agricultural Sciences, Dazhou, Sichuan, China
}

\begin{abstract}
This paper describes the major physiological changes after the loquat harvest, and the most recent year delay on postharvest technologies and principles to reduce postharvest loquat fruit quality made elaborate.
\end{abstract}

\section{Introduction}

Loquat is an evergreen tree of rosaceae, native to China and mainly distributed in the provinces south of the Yangtze River, is a rare and rare tree species in the south of China. Loquat matures from spring to early summer, which coincides with the off-season of fresh fruit supply in the middle of the year. Early-maturing loquat is known as "the first fruit in early spring" in the south. Loquat fruit color is orange yellow, and the fruit meat is soft and juiceous, with unique flavor and is widely loved, moreover, the nutritional value of loquat fruit is also very high. Loquat fruit is rich in calcium, phosphorus, VC, iron and carrot slices, in which the content of carrot and phosphorus is higher than that of citrus, banana and pineapple [1].

However, the early summer in the south is hot and wet, so it is not resistant to storage and transportation, and generally stored at room temperature for less than 20 days, it will lose water wrinkle or decay, thus losing its edible value. Therefore, in order to achieve high yield of loquat, realize long-distance transportation, increase economic benefit and do a good job of preservation, it is of great practical significance.

\section{Main physiological changes after harvest}

Loquat fruit has no post-harvest ripening, so it is necessary to wait until the fruit is basically ripe before it can be collected. With the prolongation of storage period after harvest, the main sensory changes of Loquat were that the pulp became hard, the pericarp was difficult to peel, and gradually lost water, browned or even rotted. The main physiological changes are as follows.

\subsection{Changes in respiration and ethylene production}

Zheng Yonghua et al. [2] pointed out that loquat was a non-jump fruit, and the postharvest respiration rate and ethylene production showed a downward trend. Low temperature has obvious inhibitory effect on respiratory rate and ethylene content. The respiration rate of loquat fruit is very high when it is just descending. It will decrease rapidly with the increase of time, and then it will decrease slowly. The change in later stage of storage is relatively flat. In general, the change trend is that the lower the storage temperature is lower the respiration intensity is [3].

\subsection{Changes in organic acids and sugar}

During postharvest storage of loquat fruit, vitamin C, total sugar, sucrose and soluble solids all decreased gradually with the prolongation of storage time [4]. In the respiration of loquat fruits, acid is mainly used as the matrix. Due to the sharp decline of acid, the sugar and acid ratio is increased, and the fruit flavor becomes light, which makes the acid and sweet is not suitable. Therefore, it is very important to adopt the high-efficiency storage and preservation technology to inhibit the deterioration of loquat fruit.

\subsection{Cell membrane permeability}

After harvest, with the prolongation of storage period, the membrane system was destroyed due to ethylene and other senescence factors, which led to the increase of ion leakage, and the relative conductivity of loquat fruit increased gradually with the prolongation of storage time [5]. At $1{ }^{\circ} \mathrm{C}-20{ }^{\circ} \mathrm{C}$, the lower the temperature, the smaller the change of conductivity. However, low temperature to cold injury can cause the damage of membrane system and increase the electrical conductivity, which is manifested as non-cold sensitive fruit.

\section{4 changes in fruit firmness and lignification}

Loquat has no post-ripening effect, so it is necessary to basically mature on the tree before harvest. The degradation of original pectin and the process of pulp soften are basically completed before harvest, and the

\footnotetext{
amqq198754@163.com, b2670042314@qq.com, ${ }^{\mathrm{c}} 1186884797 @$ @q.com,

d2574109089@qq.com, ${ }^{e 745358474 @ q q . c o m ~}$
} 
firmness of pulp decreases when stored at room temperature. However, when the fruit was stored at $1{ }^{\circ} \mathrm{C}$, the activity of phenylalanine ammonia lyase (PAL), one of the key enzymes of lignin synthesis, increased, the firmness of the fruit increased gradually, and the juice yield decreased. The contents of propectin, lignin and cellulose increased with the prolongation of storage period, so the pulp was easy to lignify at low temperature, resulting in difficult peeling of pericarp, increased firmness, rough fruit, less juice and so on.

\subsection{Fruit browning}

Loquat fruit contains more polyphenols, and the (PPO) activity of polyphenol oxidase in loquat fruit is also high, which can catalyze the oxidation of polyphenols and lead to tissue browning. The activity of PPO in loquat fruit increased during general cold storage, and the activity of peroxide (POD) in fruit also increased during storage, which could also lead to browning of loquat fruit [7].

\section{Postharvest storage and preservation technology}

\subsection{Preservation of Loquat with volatile Oil from Maple Leaf}

The quality loss rate, hardness and soluble solids content of loquat fruit directly determine the intrinsic quality of loquat fruit, and they directly affect the flavor and nutritional value of loquat [8]. Different concentrations of maple leaf volatile oil treatment can effectively slow down the decline rate of quality loss rate and soluble solid content of loquat fruit, delay the increase of loquat fruit firmness in a certain range, and inhibit the content of malondialdehyde (MDA), lignin content, POD activity and PAL activity in loquat fruit to varying degrees. These indexes are closely related to the ripening and senescence and lignification of loquat fruit.

\subsection{Preservation Technology of Loquat by Heat treatment}

Heat treatment kills the pathogen on the fruit surface or inhibits the activity of the pathogen and changes the enzyme activity in an appropriate way and temperature, so as to change the structural characteristics of the fruit surface, inhibit the decay of the fruit, and achieve the effect of storage and preservation. After drying with hot water $\left(48{ }^{\circ} \mathrm{C}-52{ }^{\circ} \mathrm{C}, 10 \mathrm{~min}\right)$, and then hot air $\left(38{ }^{\circ} \mathrm{C}, 24\right.$ h) before storage, the key indexes of fruit quality were obviously improved, especially the decay index decreased significantly, the soluble solid content increased steadily, the titratable acid content decreased slowly, the fruit flavor gradually became thicker, and it was not easy to lose water, and the fruit quality and commodity value were still maintained for 30 days. The adverse effect of single hot water or hot air treatment [9] is avoided. Therefore, comprehensive heat treatment combined with low temperature cold storage is an effective measure to prolong the storage period of Baiyu loquat and maintain fruit quality.

\subsection{Preservation Technology of Loquat by coating}

Chitosan is a degradation product of chitin deacetylation group, which has been used in the preservation of fruits and vegetables such as Gongpear, apricot and cucumber [10-12]. It is found that the nanocomposite film prepared by montmorillonite can not only improve the tensile strength and break extension of chitosan composite membrane, but also has certain bacteriostatic properties [13-14]. Chitosan and nano-montmorillonite were used as composite coating agents to study the fresh-keeping effect of loquat at room temperature. The results showed that chitosan / nano-montmorillonite composite coating could obviously delay water loss, inhibit the decrease of hardness, VC content, total sugar content and total acid content, and effectively prolong the shelf life of loquat [15].

\section{4 fresh-keeping Technology of Loquat by Ozone}

Ozone gas can slow down the physiological aging process of fruits and vegetables, so as to achieve fresh-keeping effect. Due to the self-decomposition nature of ozone gas, keeping loquat fresh with ozone gas will not produce any pollution. The results showed that $1.00 \mathrm{mg} / \mathrm{m}^{3}$ ozone treatment had a certain effect on postharvest storage of big five-pointed star loquat, while $150 \mathrm{mg} / \mathrm{m}^{3}$ ozone treatment had the best effect on the storage and preservation of big five-pointed star loquat, and too high concentration ozone treatment $\left(200 \mathrm{mg} / \mathrm{m}^{3}\right.$ ozone treatment) would cause damage to big five-pointed star loquat [16]. Liu Guoling et al. [17] showed that Loquat-Shaped Cakeundefineds practical $0.4 \mathrm{mg} / \mathrm{L}$ ozone water treatment combined with low temperature storage at $4{ }^{\circ} \mathrm{C}$ could significantly inhibit fruit water loss, delay fruit soluble solids, titrate acid and VC content, maintain fresh appearance and quality of fruit, and store fruit for more than 20 days.

\section{5 fresh-keeping Technology of Eriobotrya loquat by microorganisms}

The results of Zhang Suqin et al. [18] showed when the concentration of nisin was $\geq 200 \mathrm{mg} / \mathrm{L}$, the preservation effect of loquat was the best. Che Jianmei et al. [19] added $2 \%$ Agar and $2 \%-5 \% \mathrm{NaCl}$ to the fermentation broth of Bacillus brevis FJAT-0809-GLX with fresh-keeping function, and made the suspension of microbial fresh-keeping bacteria with high living bacteria content, uniform texture, no upper and lower stratification, and good stability. The results showed that the microbial preservative preparation had a good fresh-keeping effect on 'Zaozhong No. 6' and 'Jiefangzhong' loquat fruit. When stored at room temperature for 8 days $\left(20{ }^{\circ} \mathrm{C}-25^{\circ} \mathrm{C}\right)$, the weight loss rate was significantly reduced and the good fruit rate was 
increased. The results of acute toxicity test and analysis of the preparation were non-toxic grade.

\section{6 techniques of keeping Loquat fresh by controlled atmosphere Storage}

The effects of controlled atmosphere (Controlled Atmosphere, CA) storage on ethylene release, membrane lipid metabolism and senescence of fruit quality respiration, membrane lipid metabolism and other physiological and biochemical metabolic activities have been reported [20]. The results showed that controlled atmosphere storage could significantly inhibit the decrease of total acid content, delay the decrease of soluble solid content, and maintain high activities of POD and SOD. Under the condition of storage at $6{ }^{\circ} \mathrm{C}$, the suitable gas composition for controlled atmosphere storage was $\mathrm{O}_{2} 4 \%-6 \%$ and $\mathrm{C}_{2} 6 \%-8 \%$ [21].

\section{Research and prospect}

Loquat, as one of the specialty fruits in our country, has high economic value, planting area and yield are increasing day by day. Scholars at home and abroad have carried on extensive research on its postharvest physiology and preservation technology, which has been developed from traditional cold storage, chemical physical or biological natural preservation and physical, chemical and biological preservation. Although the above storage methods have a certain fresh-keeping effect, but there are defects. Many studies are only in the laboratory stage, it is difficult to popularize and use in production. Therefore, in order to make the storage and preservation get better results, we should carry on the comprehensive research and improvement from many channels and many aspects.

\section{References}

1. R.X. Lee, L.X. Li, H.Y. Zhang. Preserving and fresh keeping loquat $[\mathrm{J}]$. China Fruit and Vegetable, 2003(2): 24-25.

2. Y.H. Zheng, Y.F. Xi. A study on the relationship between the changes of postharvest membrane permeability, respirationrate, and ethylene production and the storability of loquat fruit [J]. Acta Agriculturae Universitatis Jiangxiensis, 1999, 21(1): 80-81.

3. W.X. Lee, Z.G. He, X.Z. Lin. The effect of low-temperature storage on the postharvest physiology of Loquat [J]. Journal of South China Tropical Agricultural University, 2005, 11(3): 1-4.

4. Z.M. Lu, W.X. Wu, Z.L. Zhang, et al. Study on fresh-keeping effects of loquat in various low temperature [J]. Journal of Refrigeration, 2004, 25(3): 15-18.

5. Z.M. Huang. Physiological changes of loquat fruit after harvest and its harvest and fresh preservation technology $[\mathrm{J}]$. Fujian Agricultural Science and
Technology, 2003(1): 13-14.

6. Z.M. Huang. Postharvest physiology and storage of loquat fruit $[\mathrm{J}]$. Journal of Putian Univeristy, 2003, 10(3): 26-29.

7. Y.H. Zheng, S.Y. Lee, Y.F. Xi. Changes of cell wall substances in relation to flesh woodiness in cold stored loquat fruits [J]. Acta Phytophysiologica Sinica, 2000, 26(4): 306-310.

8. Y.J. Zeng, H.S. Xiao. A review of advances in study of postharvest physiology and preservation technique of loquat [J]. Subtropical Plant Science, 2002, 31(1): 68-72.

9. H.L. Qie, S.C. Liang. Effect of hot air treatment on storage of white loquat [J]. Journal of Anhui Agricultural Sciences, 2010, 38(2): 898-899.

10. X.R. Liu, J.L. Zhou, M. Zheng. A study on the effect of chitosan coating on pear preservation [J]. Food Research and Development, 2008, 29(10): 132-134.

11. Y.X. Zhuang, J. Pang, S.Q. Liao, et al. Effect of storage on pastharvest loquat fruit $[\mathrm{J}]$. Storage and Process, 2003, 6(3): 22-23.

12. L.H. Zhao, L.P. Liu, Y. Ma. Preservation of apricot by chitosan nano-zinc oxide film [J]. Food Research and Development, 2009, 30(2): 126-127.

13. D. Shen, R.C. Chen, M.L. Wang, et al. Study on the multiple coating material of chitosan, siox nanoparticals and single stearic acid glycerine ester in the preservation of cucumbers [J]. Food and Fermentation Industries, 2006, 32(12): 164-166.

14. J.W. Rhim, S.I. Hong, H.M. Park, et al. Preparation and characterization of chitosan-based nanocomposite films with antimicrobial activity [J]. Journal of Agricultural \& Food Chemistry, 2006, 54(16): 5814-5822.

15. S. Rungsinee, S.I. Hong, D.J. An, et al. Effect of clay content on the physical and antimicrobial properties of whey protein isolate/organo-clay composite films [J]. LWT-Food Science and Technology, 2010, 43(2): 279-284.

16. Z.Z. Zhang, W. Qin, T.T. Fu, et al. Effects of ozone treatment on the preservation of loquat cultivar big five-pointed star during storage [C]. Sichuan Agricultural University\& Rural Development Bureau of Longquanyi District, Chengdu, Sichuan Province, 2014: 25-30.

17. G.L. Liu, J.N. Liu. Study on ozone keeping freshness technique of loquat fruits $[\mathrm{J}]$. Storage and Process, 2007, 7(2): 27-28.

18. S.Q. Zhang, J.J. Zhou. Application of nisin in loquat fresh-keeping $[\mathrm{J}]$. Jiangsu Agricultural Sciences, 2010(5): 401-402.

19. J.M. Che, X.F. Zheng, B. Liu, et al. Preparation of brevibacillus brevis fjat-0809-glx angent and study on its effect on loquats (eriobotryajaponica) [J]. Storage and Process, 2011, 11(5): 6-9.

20. S. Lurie, Edna Pesis. Effect of acetaldehyde and anaerobiosis as postharvest treatments on the quality of peaches and nectarines $[\mathrm{J}]$. Postharvest Biology \& 
Technology, 1992, 1(4): 317-326.

21. Y.J. Qiao, H.H. Wang, Q. Fang, et al. Effect of cold storage on quality of mopan persimmon [J]. Storage \& Process, 2007, 7(5): 18-21. 